\title{
Quantile Regression Analysis of Corporate Liquidity: Evidence from the U.S. Property-Liability Insurance Industry
}

\author{
Vincent Y. Chang a and Jeffrey Tzuhao Tsai ${ }^{\mathrm{b}}$ \\ ${ }^{a}$ Department of Insurance, Chaoyang University of Technology, 168, Jifong E. Road, Wufong District, \\ Taichung, Taiwan 41349, R.O.C. \\ Email: vcchang@cyut.edu.tw \\ ${ }^{\mathrm{b}}$ Department of Quantitative Finance, National Tsing Hua University, No. 101, Section 2, Kuang-Fu Road, \\ Hsinchu, Taiwan 30013, R.O.C. \\ Email: thtsai@mx.nthu.edu.tw
}

This study analyses the determinants of corporate liquidity for the U.S. property-liability insurance industry from 2006 to 2010. Unlike previous studies using the ordinary least squares (OLS) approach, this study applies the quantile regression (QR) method. The QR method provides further insights on how insurers' liquidity level is determined, especially for the firms at the lower and the higher quantiles. We found that leverage and organisational structure have opposite effects on insurers' liquidity in the lower and the higher quantile groups. The empirical results also show that most firm-specific characteristics and macroeconomic conditions influence the insurers' liquidity, which are consistent with the findings of the OLS approach in previous studies.

The Geneva Papers (2014) 39, 77-89. doi:10.1057/gpp.2012.46

Keywords: corporate liquidity; insurer's liquidity; quantile regression; firm-specific characteristics

Article submitted 1 December 2011; accepted 8 October 2012; published online 13 February 2013

\section{Introduction}

Liquidity maintenance has been an important issue in the corporate finance regime for both non-financial firms and financial institutions. Why do property-liability insurers need to maintain liquidity? The literature has proposed many concrete explanations, such as the investment opportunity theory, the cost of financial distress and bankruptcy theory, the efficiency argument, the agency cost hypothesis, concern regarding financial ratings, and for cash-holding purposes. ${ }^{1}$ The fact that insurers with higher liquidity operate inefficiently ${ }^{2}$ but are associated with higher financial ratings has been proposed and verified in the literature. ${ }^{3}$ Firm-specific characteristics (size, leverage, loss reserves, claim ratio, reinsurance, business concentrations and organisational

\footnotetext{
${ }^{1}$ John (1993); Kim et al. (1998); Almeida et al. (2002); Bruinshoofd and Kool (2002); Dittmar et al. (2002); Opler et al. (1999); Ozkan and Ozkan (2004); Colquitt et al. (1999).

2 Adams and Buckle (2003).

${ }^{3}$ Gaver and Poitter (2005).
} 


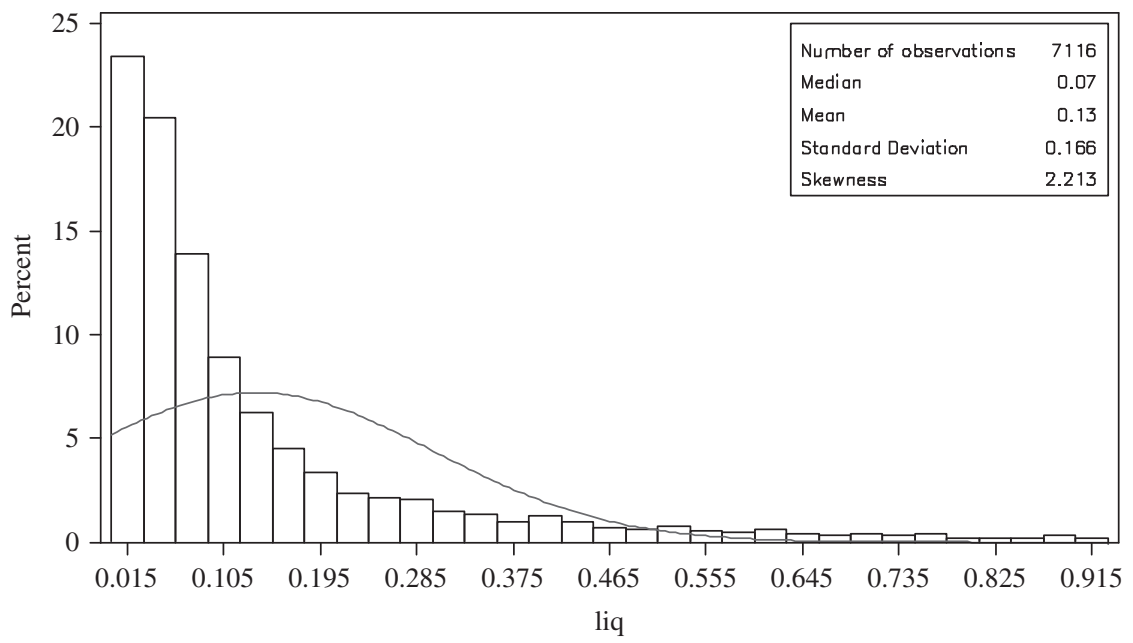

Figure 1. Frequency of the insurers' liquidity measurement ( Liq).

form) and macroeconomic factors (consumer price index (CPI) and interest rate) affecting insurers' liquidity are evidenced as well. ${ }^{4}$

The above-mentioned studies have provided much insightful evidence in determining the firms' liquidity. However, most of the analyses adopt the ordinary least squares (OLS) approach by modelling the covariates relationship between firm-specific factors and conditional mean of liquidity. To our knowledge, there are relatively few studies on insurers' liquidity using the quantile regression $(\mathrm{QR})$ approach. The $\mathrm{QR}$ approach provides alternative aspects examining various effects across insurers' liquidity quantiles and generates more information than the OLS approach.

Figure 1 plots the distribution of U.S. property-liability insurers' liquidity ( $(i q)$. The pattern shows that most insurers tend to keep lower liquidity and the histogram of insurers' liquidity is far from a normal distribution. This might result in a biased estimation when the OLS approach is used, which suggests that using the QR approach to examine the determinants of liquidity is more appropriate than using the OLS approach. The QR approach could overcome the potential defects in the OLS approach, such as the distributional misspecification and the homogeneity assumption of the dependent variable. We are also interested in the distinct effects of the explanatory variables at the lower and higher liquidity quantiles. ${ }^{5}$ Therefore, we contribute to the literature by these interesting findings of the QR approach.

It is of importance for property-liability insurers to maintain sufficient liquid assets. The short-term contract characteristics force the managers to pay more attention to the firm's liquidity and cash reserves. The property of short policy cycle casts higher cash flow volatility so that insurers must maintain sufficient liquidity to

\footnotetext{
${ }^{4}$ Shiu (2006).

${ }^{5}$ Please refer to Panel B of Table 1 for details.
} 
Table 1 Summary statistics

\begin{tabular}{|c|c|c|c|c|c|c|c|c|c|c|c|c|}
\hline \multicolumn{5}{|c|}{ Panel A Summary statistics of full sample } & \multicolumn{8}{|c|}{ Panel B Means and medians of 1st, 2nd, 3rd and 4th Liq quantlies } \\
\hline \multirow[t]{2}{*}{ Variables } & \multirow[t]{2}{*}{ Min } & \multirow[t]{2}{*}{ Mean } & \multirow[t]{2}{*}{ Median } & \multirow[t]{2}{*}{$\operatorname{Max}$} & \multicolumn{2}{|c|}{ 1st quantile } & \multicolumn{2}{|c|}{ 2nd quantile } & \multicolumn{2}{|c|}{ 3rd quantile } & \multicolumn{2}{|c|}{ 4th quantile } \\
\hline & & & & & Mean & Median & Mean & Median & Mean & Median & Mean & Median \\
\hline \multicolumn{13}{|l|}{ Dependent variable } \\
\hline Liq & $0.0000^{\mathrm{a}}$ & 0.1350 & 0.0714 & 0.9263 & 0.0165 & 0.0165 & 0.0501 & 0.0494 & 0.1082 & 0.1033 & 0.3651 & 0.3037 \\
\hline Reins & 0.0000 & 0.3651 & 0.3165 & 0.9632 & 0.3760 & 0.3390 & 0.3610 & 0.3117 & 0.3491 & 0.2887 & 0.3743 & 0.3393 \\
\hline Leverage & 0.0373 & 0.5558 & 0.5856 & 0.8931 & 0.5767 & 0.6151 & 0.5731 & 0.5924 & 0.5435 & 0.5682 & 0.5299 & 0.5615 \\
\hline Bus_H & 0.1340 & 0.5770 & 0.5133 & 1.0000 & 0.4830 & 0.3902 & 0.5382 & 0.4600 & 0.6036 & 0.5409 & 0.6830 & 0.6690 \\
\hline Geo_H & 0.0408 & 0.5823 & 0.5694 & 1.0000 & 0.4788 & 0.3600 & 0.5260 & 0.4327 & 0.6352 & 0.7827 & 0.6894 & 0.9629 \\
\hline 2_years_loss $\mathrm{b}$ & -0.5460 & -0.0481 & -0.0353 & 0.5564 & -0.0542 & -0.0425 & -0.0520 & -0.0386 & -0.0483 & -0.0338 & -0.0377 & -0.0233 \\
\hline Size & 14.1592 & 18.3057 & 18.2088 & 23.4358 & 19.3510 & 19.3522 & 18.8786 & 18.9238 & 17.8806 & 17.7605 & 17.1125 & 16.9335 \\
\hline Stock & 0.0000 & 0.6699 & 1.0000 & 1.0000 & 0.7111 & 1.0000 & 0.6976 & 1.0000 & 0.6223 & 1.0000 & 0.6487 & 1.0000 \\
\hline Single & 0.0000 & 0.4023 & 0.0000 & 1.0000 & 0.2001 & 0.0000 & 0.3030 & 0.0000 & 0.5076 & 1.0000 & 0.5987 & 1.0000 \\
\hline$S t d \_c f$ & 0.0004 & 0.0505 & 0.0298 & 0.3589 & 0.0244 & 0.0125 & 0.0309 & 0.0196 & 0.0529 & 0.0368 & 0.0938 & 0.0753 \\
\hline Growth & -1.0903 & 0.0222 & 0.0063 & 1.5034 & 0.0051 & 0.0021 & 0.0066 & -0.0006 & 0.0227 & 0.0070 & 0.0546 & 0.0298 \\
\hline Lia_reserves & 0.0000 & 0.8576 & 0.9590 & 1.0000 & 0.9082 & 0.9583 & 0.8829 & 0.9612 & 0.8382 & 0.9582 & 0.8012 & 0.9569 \\
\hline Property_reserves & 0.0000 & 0.2833 & 0.1465 & 1.0000 & 0.2239 & 0.1568 & 0.2636 & 0.1607 & 0.3241 & 0.1285 & 0.3215 & 0.1048 \\
\hline Lia_claim & 0.0000 & 0.3626 & 0.3860 & 0.8361 & 0.3971 & 0.4041 & 0.3780 & 0.3955 & 0.3489 & 0.3713 & 0.3263 & 0.3488 \\
\hline Property_claim & 0.0000 & 0.2158 & 0.2022 & 0.7887 & 0.2314 & 0.2283 & 0.2204 & 0.2119 & 0.2183 & 0.1897 & 0.1930 & 0.1424 \\
\hline Fed_rate & 0.0016 & 0.0243 & 0.0192 & 0.0502 & 0.0245 & 0.0192 & 0.0242 & 0.0192 & 0.0243 & 0.0192 & 0.0243 & 0.0192 \\
\hline$C P I$ & 0.0010 & 0.0218 & 0.0250 & 0.0410 & 0.0226 & 0.0250 & 0.0221 & 0.0250 & 0.0212 & 0.0250 & 0.0212 & 0.0250 \\
\hline Firm-year observations & 7,116 & & & & 1,779 & & 1,779 & & 1,779 & & 1,779 & \\
\hline
\end{tabular}

${ }^{\mathrm{a}}$ The minimum value of $\operatorname{Liq}$ equals to $1.62 * 10^{-5}$ rather than 0 .

${ }^{\mathrm{b}}$ The values of 2 years_loss showed in the table are the original values times $10^{3}$. 
mitigate liquidity risk. In the event of catastrophes and the global financial crisis, insurers also have to prepare additional liquidity for unexpected cash demand. ${ }^{6}$ Consequently, it is crucial to examine liquidity decision for the property-liability insurance industry.

This study uses the unbalanced panel data reported by the National Association of Insurance Commissioners (NAIC) from 2006 to 2010 to show that many firm-specific characteristic and macroeconomic factors affect insurers' liquidity. The empirical results in the fourth section show that leverage and organisational form have opposite effects on insurers' liquidity at lower and higher quantiles. For the insurers at the higher liquidity quantiles, leverage is identified as a substitute for liquidity maintenance, which indicates the higher leverage, the lower insurers' liquidity; ${ }^{7}$ however, the insurers at the lower liquidity quantiles, to avoid bankruptcy costs and financial pressure, tend to maintain higher liquidity while their leverage increases. On the organisational form, at the lower liquidity quantiles, stock insurers possess lower liquidity than mutual insurers, because stock insurers tend to have more flexible financing abilities than mutual insurers in the capital market. At the higher liquidity quantiles, stock insurers maintaining higher liquidities are observed. The plausible explanation is that when agency costs of debt are higher, firms prefer to maintain higher liquidity to finance investment opportunities instead of using external funds. ${ }^{8}$

The remainder of this paper is organised as follows: the next section illustrates the variables used and discusses predictions; the subsequent section briefly discusses the methodology; the penultimate section details and interprets the data and empirical results and the last section presents the conclusion.

\section{Variables and hypotheses}

We first explain the variables in the regression model and the hypotheses behind them. Insurers' liquidity, the dependent variable, is defined as the sum of cash and short-term invested assets divided by total assets. 9,10

On the selection of independent variables, the literature suggests that large insurers tend to have a lower liquidity level than small insurers. The natural logarithm of total assets (Size) is used to measure the firm size. ${ }^{11}$ Debt can also be regarded as a ready

\footnotetext{
${ }^{6}$ We thank the anonymous reviewer who notes that there is little possibility of a "run on the bank" for property-liability insurers. However, during a global financial crisis, financial institutions encounter not only bank-run problems but also market risk and counterparty credit risk; insurers still have to prepare extra liquidity for those investment losses resulting from market risk and counterparty credit risk. Therefore, an unexpected cash demand increase is predicted during a global financial crisis.

${ }^{7}$ John (1993); Kim et al. (1998); Ferreira and Vilela (2004); Kalcheva and Lins (2007).

${ }^{8}$ Opler et al. (1999).

9 John (1993); Kim et al. (1998); Bruinshoofd and Kool (2002); Shiu (2006).

${ }^{10}$ Previous studies defined liquidity measurement as the ratio of cash plus marketable securities to total assets. Marketable securities, in general, are very liquid, as they tend to have short-term maturities (less than one year). In addition, these securities can be bought or sold with a little effect on their prices. As a result, the liquidity used in this paper is a short-term liquidity measurement rather than a long-term liquidity measurement.

${ }^{11}$ Kim et al. (1998); Bruinshoofd and Kool (2002); Opler et al. (1999); Shiu (2006).
} 
source of financing and can be used as a substitute for liquidity maintenance; a negative relationship between leverage and liquidity is predicted. ${ }^{12}$ However, the bankruptcy cost argument states that financial stress increases the need for liquidity to avoid the threat of bankruptcy. Highly leveraged firms have limited access to future debt financing and prefer a higher level of liquidity holding. ${ }^{13}$ Therefore, prediction of the relationship between liquidity and leverage is undetermined. Leverage is measured as the ratio of total liability to total assets (Leverage). ${ }^{14}$

Potential financial constraints may influence insurers' liquidity. ${ }^{4}$ Insurers with positive loss developments imply insufficient loss reserves in the future; therefore, they must increase liquidity to mitigate the potential financial constraints. However, insurers may decrease their liquidity when confronted with a negative loss development. The 2-year loss development ${ }^{15}$ (2_years_loss) is used to measure insurers' potential financial constraints.

Higher loss reserves imply a higher payment capacity of the insurers and allow them to keep a lower liquidity level. ${ }^{4}$ This indicates that loss reserves are negatively related to liquidity. The loss reserves of liability lines and the loss reserves of property lines (Lia_reserves and Property_reserves) are used to capture the loss reserves effects. They are measured as loss reserves of liability lines to total reserves and loss reserves of property lines to total reserves, respectively. ${ }^{16}$

The claim ratio of liability lines and the claim ratio of property lines (Lia_claim and Property_claim) are included in the regression model to control the influence of various claim settlement patterns. These two claim ratios are defined as the claims of

12 John (1993); Kim et al. (1998); Colquitt et al. (1999); Ferreira and Vilela (2004); Ozkan and Ozkan (2004); Kalcheva and Lins (2007).

13 de Haan (1997); Ees et al. (1998); Faulkender (2002); Panno (2003).

${ }^{14}$ John (1993), Kim et al. (1998) and Bruinshoofd and Kool (2002) use the debt ratio to proxy firm's leverage, which is defined as the ratio of total debt (long-term debt plus debt in current liabilities) to the book value of assets. The liability structure for insurers is not the same as that for non-financial firms. The components of liability for insurers are, in general, the unearned premium reserves, loss reserves and other liabilities. Even though the liability structure of insurers is different from non-financial firms, it still possesses a resembling rationale of debt. Specifically, insurer's liability reserves could be regarded as a fund borrowing from policyholders so that it inherits the main feature of debt. Insurers with higher sales growth indicate that liability and cash inflow will increase. The increasing cash inflow would lead to a liquidity decrease. Conversely, insurers with written higher net premium also tends to confront a higher amount of loss claims; thus, insurers would like to hold more liquid assets for precautionary purposes. Consequently, the total liability to total assets for measuring insurer leverage is adopted.

15 According to the five-year historical page of the NAIC Property-Casualty Database, the variable is defined as the development of estimated losses and loss expenses incurred two years before the current and prior year, scaled by the policyholders' surplus.

${ }^{16}$ According to the five-year historical page of the NAIC Property-Casualty annual statement, (1) liability lines include medical malpractice - occurrence, medical malpractice - claims-made, workers' compensation, other liability-occurrence, other liability-claims-made, products liability-occurrence and products liability-claims-made, private passenger auto liability and commercial auto liability; (2) property lines consists of fire, allied lines, inland marine, earthquake, auto physical damage, and burglary and theft, and (3) property and liability combined lines include farm-owners' multiple peril, homeowners' multiple peril, commercial multiple peril, ocean marine, aircraft (all perils), and boiler and machinery. Total loss reserves of liability lines equal $(1)+(3)$ and total loss reserves of property lines equal $(2)+(3)$. 
liability lines to premium earned and the claims of property lines to premium earned, respectively. Insurers with higher claim ratios tend to maintain higher liquidity for assured payment requirements; a positive relationship between claim ratios and liquidity is predicted.

Reinsurance provides additional liquidity to insurers so that reinsurance may be a liquidity substitute. ${ }^{17}$ However, from a behaviour point of view, risk-averse or conservative insurers may hold more liquidity and purchase more reinsurance at the same time. Therefore, the prediction between insurers' liquidity and reinsurance demand is undetermined. We use reinsurance ratio (Reins) as a proxy for insurers' reinsurance level, which is defined as the sum of the affiliated and non-affiliated reinsurance ceded, divided by the sum of direct business written and reinsurance assumed.

Business and geographic concentration are also critical firm-specific characteristics for insurers. Business and geographically diversified insurers have lower cash flow volatility than non-diversified insurers because they tend to be less impacted by a specific business loss or local economic shocks. Thus, business and geographic concentrations are predicted to be positively related to liquidity. The geographic Herfindahl index (Geo_H) and the line of business Herfindahl index (Bus_H) are used as a proxy for geographic concentration ${ }^{18}$ and line of business concentration, ${ }^{19}$ respectively.

The Single variable is applied to control the difference between affiliated and nonaffiliated firms. ${ }^{20}$ The variable is 1 if the insurer is non-affiliated and 0 if the insurer is affiliated. We consider that a firm's liquidity is more critical for a single insurer than a group insurer; thus a positive relationship between Single and liquidity is predicted.

An insurer with higher owners' agency costs may increase liquidity holding. ${ }^{2}$ Colquitt et $a .^{21}$ indicate that stock insurers could mitigate the owner-manager conflicts more effectively than mutual insurers; the raising capital hypothesis ${ }^{22}$ also supports the fact that stock insurers can raise capital with lower costs than mutual insurers. Thus, stock insurers can maintain lower liquidity than mutual insurers. The Stock dummy variable is 1 if the insurer is a stock insurer and 0 if the insurer is a mutual insurer. A negative coefficient of Stock is predicted. Conversely, Opler $e t$ al. ${ }^{8}$ argue that when agency costs of debt are high, firms prefer to maintain higher cash holdings to finance investment opportunities without the requiring of external funds. In addition, stock insurers generally have higher agency cost of debt than mutual insurers. Thus, they propose that stock insurers should hold more cash or liquidity than mutual insurers. In sum, the relation between organisational form and liquidity is ambiguous.

\footnotetext{
${ }^{17} \mathrm{Hau}(2006)$.

${ }^{18}$ The definition of the geographic Herfindahl index follows Kim, Mayers and Smith (1996), who define it as the sum of the squares of the ratio of the dollar amount of direct business in state $j$ to the total amount of direct business across all states.

${ }^{19}$ Similar to the geographic Herfindahl index, the business Herfindahl index is defined as the sum of the squares of the ratio of the dollar amount of direct business written in a particular line of insurance to the dollar amount of direct business across all 26 lines of insurance.

${ }^{20}$ Colquitt et al. (1999); Shiu (2006).

${ }^{21}$ Colquitt et al. (1999).

${ }^{22}$ Harrington and Niehaus (2002).
} 
The return on assets minus the risk-free rate (return on Treasury bills) Rspread measures the firm's profitability. ${ }^{23,}{ }^{24}$ Insurers with higher profitability tend to have less liquidity demand. Kim et al. ${ }^{24}$ Opler et al. ${ }^{8}$ and Colquitt et al. ${ }^{21}$ propose that firms with more volatile cash flow must maintain a higher liquidity to reduce uncertain transactional demand. A positive relationship is expected between insurers' liquidity and cash flow volatility. The cash flow variability $\left(S t d_{-} c f\right)$ measures the standard deviation of the cash flow ratio from year $t$ to year $t-2 . \overline{25}, 26$

A firm's growth opportunity may also affect its liquidity. ${ }^{27}$ If the rate of a firm's sales growth and the cash flows contributing to the firm's reserves is greater than the speed of the reserves used, a negative relationship exists between sales growth and liquidity. ${ }^{28}$ Firms with a higher sales growth rate tend to have excess liquidity reserves; hence, superfluous cash flow encourages firms to decrease their liquidity. Conversely, Colquitt et al. $^{21}$ indicate that an insurer with better future investment opportunities tends to maintain a higher level of cash so that he or she can finance projects with lower-cost internal capital. Therefore, the prediction between an insurer's growth and liquidity is ambiguous. The insurer's growth opportunity is measured by the premium earned growth rate (Growth). ${ }^{29}$

Lastly, general economic conditions influence insurers' liquidity decisions. ${ }^{30}$ When the economic condition is significantly worse or unstable, insurers prefer to retain more cash to meet the unexpected cash demand. The Federal funds effective rate $(\text { Fed_rate })^{31}$ and annual percent changes of U.S. CPI $(C P I)$ are included in the analysis. The expected signs on the interest rate and inflation are both positive.

\section{Methodology}

Traditional analysis of the determinants of corporate liquidity adopts the OLS approach (e.g. Kim et al., ${ }^{24} \mathrm{John}^{27}{ }^{27}$ Bruinshoofd and Kool, ${ }^{32}$ and Shiu ${ }^{4}$ ). The OLS approach typically depends on an a priori distributional assumption of the dependent

${ }^{23}$ The return on assets is defined as the net income plus tax and interest expense divided by total assets.

${ }^{24}$ Kim et al. (1998).

${ }^{25}$ The cash flow ratio is defined as net operating and investment income plus additional capital changes paid in (before interest, tax and dividends) divided by total assets.

${ }^{26}$ We have to note that the standard deviation of cash flow for the year 2006 is calculated from 2004 to 2006. We also use the standard deviation of the cash flow ratio over year $t$ to year $t-4$ for a robustness check. Overall, the results are similar.

27 John (1993).

${ }^{28}$ It is noteworthy that if a contradicting situation emerges, then a positive relationship between sales growth and liquidity is predicted.

${ }^{29}$ Premium earned growth rate is defined as a logarithm (premium earned $(t) /$ premium earned $(t-1)$ ). For example, the growth rate of premium earned for 2006 is defined as log (premium earned (2006)/premium earned (2005)).

${ }^{30}$ We thank the anonymous reviewer who suggests that general economic conditions (i.e. interest rate and inflation) should be taken into consideration in the QR analysis.

${ }^{31}$ We also use an alternative interest rate, 1-year T-bill rate, to implement a robustness check. The regression results are similar to the results of Federal interest rate. We do not tabulate those results here.

${ }^{32}$ Bruinshoofd and Kool (2002). 
variable. The studies use the OLS approach, accepting a homogeneous influence of the dependent variable that increases the estimation bias, especially when the impacts of the dependent variable are heterogeneous.

The QR approach introduced by Koenker and Bassett ${ }^{33}$ extends the notion of the classical least squares estimation of the conditional mean to a collection of models for different conditional quantile functions. This approach details how the conditional distribution of the dependent variable $(Y)$ depends on the covariates of independent variables $(X)$ at each quantile. The conditional quantile functions are specified as a linear function of the dependent variable:

$$
\begin{gathered}
Y=X^{\prime} \beta+\varepsilon \\
Q_{\tau}(Y \mid X=x)=x^{\prime} \beta(\tau) \text { and } \tau \in(0,1) .
\end{gathered}
$$

where $Y$ is the dependent variable, $\mathbf{X}$ is a matrix of independent variables, $\beta$ is the estimators vector, $\varepsilon$ is the error term and $Q_{\tau}(Y \mid X=x)$ denotes the $\tau$ th quantile of $Y$ conditional on $X=x$. The model also assumes that $\varepsilon$ satisfies the quantile restriction $Q_{\tau}(\varepsilon \mid X=x)=0$.

The estimator $(\hat{\beta}(\tau))$ of the QR approach is the solution to the following minimisation problem:

$$
\underset{\beta \in R^{K}}{\operatorname{Min}} \sum_{Y \geq X^{\prime} \beta} \tau\left|Y-X^{\prime} \beta\right|+\sum_{Y<X^{\prime} \beta}(1-\tau)\left|Y-X^{\prime} \beta\right| .
$$

This approach allows the researchers to estimate relationships between variables along the entire length of the conditional distribution. There are several advantages to this approach. First, the QR estimator has a comparable efficiency to the OLS estimator in Gaussian models and non-Gaussian heavy-tailed error distributions. Second, the QR approach provides a detailed assessment at the tails of the dependent variables by identifying the determinants separately. Third, this approach is used to identify non-linearity in the relationships between variables. Fourth, this approach is robust and less sensitive to the presence of outliers or skewed tails. ${ }^{34}$ Lastly, the QR approach offers a complete picture of the covariate effect when a set of percentiles is modelled, and it also captures the critical features of the database used. These advantages encourage us to adopt the QR approach to examine the determinants of U.S. property-liability insurers' liquidity.

\section{Empirical results}

\section{Data}

Our data is constructed by the property-liability insurers in the U.S. NAIC annual report from 2006 to 2010 . The numbers of insurers in the original data are 3,006. After

\footnotetext{
${ }^{33}$ Koenker and Bassett (1978).

${ }^{34}$ Koenker and Hallock (2001).
} 
deleting the missing data and unreasonable values, 2,136 insurers were considered. Values smaller than the 1st percentile and greater than the 99th percentile of the observations were also dropped except for the dummy variables. Finally, the available data includes 1,947 insurers and 7,116 firm-year observations.

Table 1 shows the summary statistics of the variables. Panel A shows that the mean of Liq is 13.5 per cent and the median is 7.14 per cent. Liq has a minimum of 0 per cent ${ }^{35}$ and a maximum of 92.63 per cent. The mean values of the independent variables are similar to the results in previous studies. For example, the variable Stock shows that about 66.99 per cent of the observations are stock insurers, whereas 40.23 per cent of the observations are non-affiliated insurers (Single). The mean of the geographic Herfindahl index is 0.5823 (Geo_H) and the insurers' cash flow volatility is approximately 5.05 per cent $\left(S t d \_c f\right)$. The descriptive statistics in Panel A indicate that the data selection is appropriate.

Panel B presents the means and medians of the independent variables in the fourclass quantiles of the insurer's liquidity. The means (medians) of Liq in the first and the fourth quantiles are 1.65 per cent ( 1.65 per cent) and 36.51 per cent (30.37 per cent), respectively. We can observe that as the liquidity quantiles increase, Bus_H, Geo_H, 2_year_loss, Single, Std_cf and Growth increase, whereas Leverage, Size, Stock, Rspread and Lia_reserves decrease. These results also encourage us to use the QR approach to examine the liquidity determinations conditional on various quantiles.

\section{Empirical results}

Both the OLS and QR approaches are implemented and the corresponding results are shown in Table 2. The Leverage coefficient is insignificant in the OLS model, whereas the Leverage coefficients in the QR model are significant at the higher and lower quantiles. The insurers at the higher quantiles $(\tau=0.9$ and 0.95$)$, leverage reports a negative relationship with insurers' liquidity, which is consistent with the substitution argument. Leverage provides a ready source of financing so that insurers use leverage as a substitute for liquidity maintenance. Significantly positive coefficients are found for insurers at lower-level liquidity $(\tau=0.05,0.1$ and 0.25$)$. The plausible explanation is that the insurers at the lower liquidity quantiles encounter more financial constraints than those at the higher liquidity quantiles and that they need to maintain sufficient liquid assets to avoid financial pressure or bankruptcy costs. ${ }^{13}$

Another interesting finding is that the OLS result provides a weak and insignificant relationship between organisational form and liquidity. However, the QR result reports a significant difference at the higher and lower liquidity quantiles. Table 2 shows that the coefficients of the Stock dummy are negative at lower and median quantiles $(\tau=0.05,0.1,0.25,0.5$ and 0.75$)$, which is consistent with the agency cost hypothesis and the raising capital argument. Conversely, contradictory results (significantly positive) are presented for insurers at the highest quantile $(\tau=0.95)$, which supports Opler et al.'s 8 argument.

\footnotetext{
${ }^{35}$ The minimum value of Liq equals $1.62 * 10^{-5}$ rather than 0 .
} 
Table 2 Empirical results

\begin{tabular}{|c|c|c|c|c|c|c|c|c|c|}
\hline & \multirow{2}{*}{$\begin{array}{l}\text { Expected } \\
\text { sign }\end{array}$} & \multirow[t]{2}{*}{$O L S$} & \multicolumn{7}{|c|}{ Quantiles $(\tau=0.05,0.1,0.25,0.5,0.75,0.9$ and 0.95$)$} \\
\hline & & & 0.05 & 0.1 & 0.25 & 0.5 & 0.75 & 0.9 & 0.95 \\
\hline Intercept & & $0.4104 * * *$ & $0.0399 * * *$ & $0.0562 * * *$ & $0.1198^{* * *}$ & $0.1899 * * *$ & $0.3075^{* * *}$ & $0.5265^{* * *}$ & $0.7148 * * *$ \\
\hline Reins & $+/-$ & $0.0181 * * *$ & -0.0017 & 0.0013 & $0.0048 * *$ & $0.0064 *$ & $0.0122 * * *$ & $0.0312 * * *$ & $0.0470 * * *$ \\
\hline Leverage & $+1-$ & 0.0133 & $0.0090^{* * *}$ & $0.0140^{* * *}$ & $0.0217^{* * *}$ & 0.0070 & 0.0046 & $-0.0525^{* *}$ & $-0.1869 * * *$ \\
\hline Bus_H & + & $0.0417^{* * *}$ & 0.0023 & 0.0012 & $0.0059^{* *}$ & $0.0067^{* *}$ & $0.0209^{* * *}$ & $0.0870^{* * *}$ & $0.1610^{* * *}$ \\
\hline Geo_H & + & 0.0026 & -0.0014 & 0.0001 & 0.0003 & $0.0042^{*}$ & 0.0046 & 0.0048 & 0.0044 \\
\hline 2_years_loss & + & $53.6417 * * *$ & 2.4107 & 6.0709 & $16.4883^{* * *}$ & $26.5388 * * *$ & $54.5402 * * *$ & $101.1457 * * *$ & $154.1267 * * *$ \\
\hline Size & - & $-0.0191^{* * *}$ & $-0.0014^{* * *}$ & $-0.0022^{* * *}$ & $-0.0045^{* * *}$ & $-0.0069 * * *$ & $-0.0122^{* * *}$ & $-0.0202 * * *$ & $-0.0266^{* * *}$ \\
\hline Stock & $+1-$ & $0.0075^{*}$ & $-0.0034 * * *$ & $-0.0029^{* * *}$ & $-0.0051^{* * *}$ & $-0.0054^{* * *}$ & $-0.0045^{*}$ & 0.0063 & $0.0418^{* * *}$ \\
\hline Single & + & $0.0329 * * *$ & $0.0056^{* * *}$ & $0.0094^{* * *}$ & $0.0133^{* * *}$ & $0.0185^{* * *}$ & $0.0326^{* * *}$ & $0.0751 * * *$ & $0.1480 * * *$ \\
\hline Rspread & - & -0.0274 & -0.0069 & $-0.0238^{*}$ & $-0.0555^{* * *}$ & $-0.0857 * * *$ & $-0.0560 *$ & -0.0946 & -0.0822 \\
\hline$S t d \_c f$ & + & $0.9608^{* * *}$ & $0.0751 * * *$ & $0.2003^{* * *}$ & $0.4086^{* * *}$ & $1.2762 * * *$ & $1.9843^{* * *}$ & $2.1448 * * *$ & $1.9237 * * *$ \\
\hline Growth & $+/-$ & $0.0245^{* * *}$ & -0.0011 & 0.0020 & $0.0065^{*}$ & $0.0083^{* *}$ & $0.0215^{* * *}$ & $0.0308 * *$ & $0.0527 * * *$ \\
\hline Lia_reserves & - & $-0.0174^{*}$ & $-0.0064 * *$ & $-0.0085^{* *}$ & $-0.0164^{* * *}$ & $-0.0171 * * *$ & $-0.0213^{* *}$ & -0.0298 & -0.0138 \\
\hline Property_reserves & - & $0.0509 * * *$ & $0.0146^{* * *}$ & $0.0230 * * *$ & $0.0340^{* * *}$ & $0.0364 * * *$ & $0.0369 * * *$ & $0.1070 * * *$ & $0.1027 * * *$ \\
\hline Lia_claim & + & -0.0177 & -0.0039 & -0.0018 & $-0.0150^{* *}$ & $-0.0319 * * *$ & $-0.0509^{* * *}$ & $-0.0476^{*}$ & 0.0192 \\
\hline Property_claim & + & $-0.0850^{* * *}$ & $-0.0178 * * *$ & $-0.0318^{* * *}$ & $-0.0422^{* * *}$ & $-0.0582 * * *$ & $-0.0543^{* * *}$ & $-0.1594 * * *$ & $-0.2016^{* * *}$ \\
\hline Fed_rate & + & 0.1068 & -0.0173 & -0.0109 & 0.0246 & 0.0492 & -0.0274 & -0.0857 & -0.0834 \\
\hline$C P \bar{I}$ & + & $-0.2902^{* *}$ & $-0.0613^{*}$ & $-0.0767^{*}$ & $-0.2529 * * *$ & $-0.3286^{* * *}$ & -0.0950 & -0.1670 & $-0.5179^{*}$ \\
\hline Firm-year observations & & 7,116 & & & & & & & \\
\hline
\end{tabular}

This table presents the results of the OLS approach (column 3) and of the QR approach with quantiles $\tau=0.05,0.1,0.25,0.5,0.75,0.9$ and 0.95 (column $4 \sim 10$ ). The dependent variable is the insurers' liquidity $(L i q)$. Column 2 reports the prediction signs of firm-specific characteristics and macroeconomic factors.

Note: $* * * * *$ and $*$ represent statistical significance at the 1 per cent, 5 per cent and 10 per cent levels, respectively. 
In Table 2, we also observe that for both the OLS and the QR models, the insurer's growth opportunity (Growth) is positively related to liquidity. The result is consistent with the argument proposed by Colquitt et $a .^{21}$ that insurers with greater future investment opportunities tend to maintain higher levels of liquidity.

We find that the coefficients of the Reins variable are significantly positive for both the OLS and the QR models, which is inconsistent with the argument of Hau. ${ }^{17}$ The reason is that insurers treat the reinsurance contract as a risk diversification tool and conservative insurers (at the higher quantiles) purchase more reinsurance and hold more liquidity. Therefore, Reins coefficients are significantly positive.

Some independent variables are significant for both the OLS and the QR results: Liquidity is positively related to Bus_H, 2_years_loss, Single and Std_cf, and negatively related to Size, Rspread and Lia_reserves. The positive coefficients for Bus_H indicate that insurers with a higher business concentration tend to hold more liquid assets to mitigate the unexpected claims demand. Insurers hold more liquid assets when they confront higher loss development (2_years_loss; insufficient loss reserve), which supports the financial constraints argument. Single insurers (Single) and insurers with higher cash flow volatility $\left(S t d \_f f\right)$ tend to maintain higher liquidity so that they can effectively mitigate financial pressure and reduce the probability of insolvency. ${ }^{36}$

The coefficients of Size are negative and significant, consistent with the predictions of Kim et al. ${ }^{24}$ Bruinshoofd and Kool, ${ }^{32}$ Opler et al. ${ }^{8}$ and Shiu. ${ }^{4}$ Larger insurers have a better reputation or credit rating than smaller insurers so that they can obtain funds easily if they confront unexpected cash needs. Thus, larger insurers can maintain lower liquidity than small insurers.

The empirical results also show that Rspread has a significantly negative relationship with liquidity, which is consistent with the finding of Kim et al. ${ }^{24}$ The negative coefficient of Lia_reserves indicates that insurers with higher loss reserves tend to have higher payment capacities so that they are inclined to maintain lower liquidity. Nevertheless, Property_reserves variable presents an undesired expectation.

We predict that insurers with higher claim ratios maintain higher liquidity to meet the assured payment requirements. However, the results of Lia_claim and Property_ claim are inconsistent with the predictions. We conjecture that if claims are "ex-ante payment", insurers tend to maintain higher liquidity for claims payout in the future. Conversely, if claims are "ex post payment", indemnities decrease a firm's cash holdings and result in insurers in a lower liquidity. The results tend to support the perspective of "ex post payment".

\section{Conclusion}

Instead of using the traditional OLS approach, this study proposes the QR approach to examine the determinants of insurers' liquidity. Consistent with the literature, ${ }^{37}$ our

\footnotetext{
${ }^{36}$ Kim et al. (1998); Opler et al. (1999).

${ }^{37}$ Kim et al. (1998); Opler et al. (1999); Bruinshoofd and Kool (2002); Mehar (2005); Shiu (2006).
} 
evidence shows that insurers' liquidity is determined by a majority of firm-specific characteristics and macroeconomic conditions.

The evidence shows that leverage and organisational form present a significantly different impact on insurers' liquidity at the lower and the higher liquidity quantiles. These results are in contrast to the results of the OLS approach. For insurers at the higher quantiles, the substitute argument is supported and the relation between leverage and liquidity is negative; insurers at the lower quantiles, upon encountering financial pressure and bankruptcy costs, increase their liquidity when leverage increases and a positive relationship exists. On the organisational form, at the lower quantiles, the agency cost hypothesis and the raising capital argument are supported, stock insurers maintain less liquidity than do mutual insurers. Nevertheless, at the higher quantiles, stock insurers maintain higher liquidity than mutual insurers in order to take advantage of the investment opportunities without acquiring external funds.

Other major findings are summarised below. First, the evidence shows that insurers with greater future investment opportunities maintain higher levels of liquidity. Second, reinsurance is regarded as a risk diversification tool and reinsurance purchase is positively related to liquidity at the higher quantiles. Third, business concentration, loss development, single insurer and cash flow volatility are all positively related to insurers' liquidity whereas firm size, return spread and reserves of liability lines have a reserve impact on liquidity. Lastly, the signs of claim ratio and inflation are opposed to our predictions.

The practical implications of this study are as follows. First, for the insurers' liquidity at the lower quantiles, policyholders, policymakers and/or regulators should pay more attention to assess the insurers' financial pressure and liquidity constraint. Second, the OLS approach provides an insufficient explanation on the determinants of insurers' liquidity; the QR analysis provides an extraordinary explanation on insurers' liquidity at the lower and the higher quantiles of the distribution. In summary, to correctly assess insurers' liquidity, we suggest considering not only the results of the OLS approach but also that of the QR approach.

\section{References}

Adams, M. and Buckle, M. (2003) 'The determinants of operational performance in the Bermuda insurance market', Applied Financial Economics 13(2): 133-143.

Almeida, H., Campello, M. and Weisbach, M.S. (2002) Corporate demand for liquidity: A theory and some evidence, Working Paper No. 9253, National Bureau of Economic Research (NBER), Cambridge, MA

Bruinshoofd, A. and Kool, C. (2002) The determinants of corporate liquidity in the Netherlands, Working Paper, Maastricht University.

Colquitt, L.L., Sommer, D.W. and Godwin, N.H. (1999) 'Determinants of Cash Holdings by PropertyLiability Insurers', Journal of Risk and Insurance 66(3): 401-415.

de Haan, L. (1997) Financial Behaviour of the Dutch Corporate Sector, Amsterdam: Thela Thesis.

Dittmar, A.K., Smith, J.M. and Servaes, H. (2002) Corporate liquidity, Discussion Paper No. 3499, Centre for Economic Policy Research, London.

Ees, H.V., Garretsen, H., Haan, L.D. and Sterken, E. (1998) 'Investment and debt constraints: Evidence from Dutch panel data', in S. Brakman, H. van Ees and S.K. Kuipers (eds.) Market Behaviour and Macroeconomic Modelling, London: Macmillan Press, pp. 159-179.

Faulkender, M. (2002) Cash holdings among small businesses, Working Paper.

Ferreira, M.A. and Vilela, A.S. (2004) 'Why do firms hold cash? Evidence from EMU countries', European Financial Management 10(2): 295-319. 
Gaver, J.J. and Poitter, S.W. (2005) 'The role of holding company financial information in the insurer-rating process: Evidence from the property-liability industry', Journal of Risk and Insurance 72(1): 77-103.

Harrington, S.E. and Niehaus, G. (2002) 'Capital structure decisions in the insurance industry: Stocks versus mutuals', Journal of Financial Services Research 21(1-2): 145-163.

Hau, A. (2006) 'The liquidity demand for corporate property insurance', Journal of Risk and Insurance 73(2): 261-278.

John, T.A. (1993) 'Accounting measures of corporate liquidity, leverage, and costs of financial distress', Financial Management 22(3): 91-100.

Kalcheva, I. and Lins, K.V. (2007) 'International evidence on cash holdings and expected managerial agency problems', Review of Financial Studies 20(4): 1087-1112.

Kim, W.J., Mayers, D. and Smith, C.W. (1996) 'On the Choice of Insurance Distribution Systems', Journal of Risk and Insurance 63(2): 207-227.

Kim, C.S., Mauer, D.C. and Sherman, A.E. (1998) 'The determinants of corporate liquidity: Theory and evidence', Journal of Financial and Quantitative Analysis 33(3): 335-359.

Koenker, R. and Bassett, G. (1978) 'Regression quantiles', Econometrica 46(1): 33-50.

Koenker, R. and Hallock, K. (2001) 'Quantile regression', Journal of Economic Perspectives 15(4): $143-156$.

Mehar, A. (2005) 'Impacts of equity financing on liquidity position of a firm', Applied Financial Economics 15(6): 425-438.

Opler, T., Pinkowitz, L., Stulz, R. and Williamson, R. (1999) 'The determinants and implications of corporate cash holdings', Journal of Financial Economics 52(1): 3-46.

Ozkan, A. and Ozkan, N. (2004) 'Corporate cash holdings: An empirical investigation of UK companies', Journal of Banking and Finance 28(9): 2103-2134.

Panno, A. (2003) 'An empirical investigation on the determinants of capital structure: The UK and Italian experience', Applied Financial Economics 13(2): 97-112.

Shiu, Y.M. (2006) 'Corporate liquidity: Evidence from the United Kingdom life insurance industry', Applied Economics Letters 13(15): 993-998.

\section{About the Authors}

Vincent Y. Chang is the Assistant Professor in the Insurance Department at Chaoyang University of Technology in Taiwan.

Jeffrey Tzuhao Tsai is the Assistant Professor in the Quantitative Finance Department at National Tsing Hua University in Taiwan. 